\title{
Short communication: Effect of active food packaging materials on fluid milk quality and shelf life
}

\author{
Dana E. Wong and Julie M. Goddard ${ }^{1}$ \\ Department of Food Science, University of Massachusetts, Amherst 01003
}

\begin{abstract}
Active packaging, in which active agents are embedded into or on the surface of food packaging materials, can enhance the nutritive value, economics, and stability of food, as well as enable in-package processing. In one embodiment of active food packaging, lactase was covalently immobilized onto packaging films for in-package lactose hydrolysis. In prior work, lactase was covalently bound to low-density polyethylene using polyethyleneimine and glutaraldehyde cross-linkers to form the packaging film. Because of the potential contaminants of proteases, lipases, and spoilage organisms in typical enzyme preparations, the goal of the current work was to determine the effect of immobilized-lactase active packaging technology on unanticipated side effects, such as shortened shelf-life and reduced product quality. Results suggested no evidence of lipase or protease activity on the active packaging films, indicating that such active packaging films could enable in-package lactose hydrolysis without adversely affecting product quality in terms of dairy protein or lipid stability. Storage stability studies indicated that lactase did not migrate from the film over a 49-d period, and that dry storage resulted in $13.41 \%$ retained activity, whereas wet storage conditions enabled retention of $62.52 \%$ activity. Results of a standard plate count indicated that the film modification reagents introduced minor microbial contamination; however, the microbial population remained under the $20,000 \mathrm{cfu} / \mathrm{mL}$ limit through the manufacturer's suggested 14-d storage period for all film samples. This suggests that commercially produced immobilized lactase active packaging should use purified cross-linkers and enzymes. Characterization of unanticipated effects of active packaging on food quality reported here is important in demonstrating the commercial potential of such technologies.
\end{abstract}

Key words: lactase, immobilized enzyme, active packaging, milk quality

Received July 1, 2013.

Accepted October 5, 2013.

${ }^{1}$ Corresponding author: goddard@foodsci.umass.edu

\section{Short Communication}

Lactose intolerance can produce uncomfortable intestinal symptoms, which can be prevented by consuming lactose-free products (Vesa et al., 2000; Swallow, 2003; Matthews et al., 2005). Traditionally lactose-free fluid milk is produced by the addition of $\beta$-galactosidase to fluid pasteurized milk in a batch operation that requires a secondary heat treatment to deactivate the enzyme and to inactivate any microbial or enzymatic contamination from the enzyme preparation. This method results in a characteristic cooked milk flavor, which can be dissatisfying to consumers (Chapman et al., 2001; Adhikari et al., 2010). Immobilized enzyme reactors have been investigated as a continuous processing alternative (Albayrak, 2002; Husain, 2010; Freitas et al., 2011). Despite the potential for reuse and recovery of the immobilized enzymes, fouling and stability concerns have limited their commercial application.

Active packaging, in which an active component is embedded into or onto a packaging material with the goal of improving the safety, economics, and shelf life of packaged foods, may offer an alternative means to produce lactose-free fluid milk products (Vermeiren et al., 1999; Fernández et al., 2008). Developments in active packaging with immobilized enzymes for dairy products are aimed at reducing the negative sensory characteristics of batch processing (Goddard et al., 2007; Mahoney et al., 2013). One such active package was created by layer-by-layer deposition of lactase, in which lactase is covalently immobilized onto a UV functionalized lowdensity polyethylene (LDPE) surface between layers of repeated depositions of polyethyleneimine (PEI) and glutaraldehyde (GL) cross-linking layers (Wong et al., 2013).

Some researchers have evaluated the intended effects of active packaging in terms of product quality, consistency, and consumer acceptance in dairy products, whereas separate comprehensive fluid milk quality studies have evaluated bacterial counts, sensory acceptance, and shelf-life of the final product (Hansen and Arora, 1990; Grosová et al., 2008; Martin et al., 2012). However, reports on novel active packaging technologies typically do not evaluate their potential 
for unanticipated adverse effects on dairy quality. As additional steps are required in the manufacture of active packaging materials, potential for the introduction of microbial and enzymatic contaminants (e.g., lipases and proteases from the enzyme preparations) exists, which can directly affect the quality and shelf stability of the packaged food products. Therefore, the overall goal of this work was to evaluate the effect of an immobilized lactase active packaging material on the quality and shelf stability of fluid milk. Ultra-high temperature pasteurized (UHT) skim milk was subjected to storage studies in contact with the active packaging material, and was evaluated for protease and lipase activity, as well as microbial growth by SPC. Migration studies and activity studies were also performed.

Additive-free LDPE pellets were purchased from Scientific Polymer Products (Ontario, NY). Anhydrous potassium phosphate dibasic, anhydrous potassium phosphate monobasic, anhydrous sodium bicarbonate, anhydrous sodium carbonate, anhydrous sodium acetate trihydrate, glacial acetic acid, hydrochloric acid, sodium hydroxide, acetone (99.8\%), isopropanol (99.9\%), methanol (99.9\%), peptone, and polytetrafluoroethylene filter units $(0.2 \mu \mathrm{m})$ were purchased from Fisher Scientific (Fairlawn, NJ). The 1-ethyl3-(3-dimethylaminopropyl) carbodiimide hydrochloride was purchased from Proteo-Chem (Denver, CO). N-Hydroxysuccinimide, sodium phosphate tribasic dodecahydrate (98\%), ortho-nitrophenol, para-nitrophenyl acetate (pNPA), and 2-( $N$-morpholino) ethanesulfonic acid (MES) were purchased from Acros Organics (Geel, Antwerp, Belgium). Glutaraldehyde (25\%) was purchased from Alfa Aesar (Ward Hill, MA). Protazyme OL tablets were purchased from Megazyme International (Bray, Ireland). Aerobic Count Plate Petrifilms were purchased from 3M (Two Harbors, MN). Ortho-nitrophenol- $\beta$-D-galactopyranoside (ONPG), bicinchoninic acid (BCA) assay reagents, and BSA were purchased from Thermo Scientific (Rockford, IL). Branched PEI (molecular weight $=25 \mathrm{kDa}$ ) and para-nitrophenol were purchased from Sigma-Aldrich (St. Louis, MO). Amicon Ultra (50k molecular weight cut-off) centrifugal filter devices were purchased from Millipore Ireland (Carrigtwohill, County Cork, Ireland). Syringe filters were purchased from Whatman (Florham Park, NJ). Hershey's UHT skim milk was purchased from Diversified Foods Inc. (Metairie, LA). Dried lactase preparation from Aspergillus oryzae was donated by Enzyme Development Corporation (New York, NY).

The lactase was purified in a $0.1 \mathrm{M}, \mathrm{pH} 5.0$ acetate buffer and filtered through a $0.2-\mu \mathrm{m}$ polytetrafluoroethylene syringe filter before centrifugal filtration $(50 \mathrm{k}$ molecular weight cut-off) at $5,015 \times g$ for $30 \mathrm{~min}$ at $20^{\circ} \mathrm{C}$. Lactase purification was performed to remove contaminating enzymes and microorganisms from the enzyme preparation, and to create a stock solution for ease of film preparation. Lactase trapped in the membrane filter was flushed out with $0.1 \mathrm{M}, \mathrm{pH} 5.0$ sodium acetate buffer and stored at $4^{\circ} \mathrm{C}$ for further use. The purified solution is heretofore referred to as the free lactase enzyme solution.

The immobilized lactase active packaging films analyzed in this study were prepared using a layer-by-layer lactase immobilization method on functionalized polyethylene as previously reported for the development of multilayer films (Wong et al., 2013). Briefly, acetone and isopropanol cleaned films $(2 \times 1 \mathrm{~cm})$ pressed from LDPE pellets on a Carver Laboratory Press (Fred S. Carver Inc., Summit, NJ) to $294 \pm 17 \mu \mathrm{m}$ were exposed to $28 \mathrm{~mW} / \mathrm{cm}^{2}$ of UV light at $254 \mathrm{~nm}$ to generate carboxylic acid groups to which branched PEI was bound using water-soluble cabodiimide chemistry to produce LDPE-PEI films. Purified lactase (LAC) was covalently linked to the amine-functionalized polyethylene using reductive animation chemistry through a GL cross-linker (LDPE-GL films). The resulting film represented a single multilayer (LDPE-LAC films). All quality and stability tests described herein were done on individual multilayer films.

The total protein content of the free lactase enzyme solution and LDPE-LAC was quantified using an altered BCA assay for film surfaces against buffer and LDPE controls. An aliquot of $10 \mu \mathrm{L}$ of free lactase enzyme solution was reacted in $2 \mathrm{~mL}$ of $\mathrm{BCA}$ working reagent for $30 \mathrm{~min}$ at $37^{\circ} \mathrm{C}$ to determine free enzyme protein content, whereas each $(2 \times 1 \mathrm{~cm})$ sample film was shaken in $3 \mathrm{~mL}$ of BCA working reagent for $1 \mathrm{~h}$ at $60^{\circ} \mathrm{C}$ (Mahoney et al., 2013). Samples were read at $562 \mathrm{~nm}$ on a Synergy 2 with Gen5 Software (BioTek Instruments Inc., Winooski, VT) and compared against a standard curve of known concentrations of BSA. Protein migration was measured by quantifying and comparing the total protein content of blank MES buffer, MES film storage buffer, LDPE films, and LDPE-LAC films following the methods for free enzyme and film content BCA assays, respectively.

Lactase activity was determined using the ONPG assay as outlined in the Foods Chemical Codex for $A$. oryzae (Institute of Medicine (US) Committee on Food Chemicals Codex, 2003). Assay conditions followed conditions for free lactase from A. oryzae with an optimum activity at $50^{\circ} \mathrm{C}$ and $\mathrm{pH} 5.0$. The lactase activity was calculated using an experimentally determined extinction coefficient $(\varepsilon)$ of $4.05 \mu \mathrm{mol} / \mathrm{mL}$ produced by a standard curve of $o$-nitrophenol $(99 \%)$ and $1 \%(\mathrm{wt} / \mathrm{vol}$ ) sodium carbonate aqueous solution (Wong et al., 2013). The resulting activity calculations in acid lactase units 
represent the cleaved ONPG in micromoles per minute. To measure the activity of lactase, individual films of LDPE-LAC and LDPE $(2 \times 1 \mathrm{~cm})$ were placed in $3 \mathrm{~mL}$ of $3.7 \mathrm{mg} / \mathrm{mL}$ ONPG in $0.1 \mathrm{M}, \mathrm{pH} 5.0$ acetate buffer for $1 \mathrm{~h}$ (films) or $15 \mathrm{~min}$ (free enzyme solution) of shaking at $50^{\circ} \mathrm{C}$. The reaction was stopped with $4 \mathrm{~mL}$ of $10 \%$ (wt/vol) sodium carbonate solution in water. Deionized water was added to make the final sample volume 10 $\mathrm{mL}$. Activity of films after storage for up to 8 wk under wet $\left(4^{\circ} \mathrm{C}\right)$ and dry conditions was also quantified. To evaluate activity under wet storage conditions, films were stored in individual sterile glass tubes containing $1 \mathrm{~mL} / \mathrm{cm}^{2} 0.1 \mathrm{M}, \mathrm{pH} 5.0 \mathrm{MES}$ buffer. For dry storage films, dried films were stored in a covered Petri dish over calcium sulfate desiccant $(<98 \%)$ at room temperature and $15 \%$ relative humidity.

Standard plate counts were used to determine the effect of film preparation on product spoilage. Each sample of LDPE and LDPE-LAC film $(2 \times 1 \mathrm{~cm})$ was stored in individual sterile glass test tubes containing 1 $\mathrm{mL} / \mathrm{cm}^{2}$ of UHT skim milk at $4^{\circ} \mathrm{C}$ with all components assembled using aseptic methods. After 0, 7, 14, and $21 \mathrm{~d}$ of storage, samples were diluted accordingly in $1 \%$ peptone water, plated on 3M Aerobic Count Plate Petrifilm, and discarded. Petrifilms were incubated at $32^{\circ} \mathrm{C}$ for $48 \mathrm{~h}$ and counted for colonies as outlined by the AOAC methods 986.33 and 989.10 for milk and dairy products (AOAC International, 2002). The UHT skim milk and LDPE films in UHT skim milk stored at the same conditions as the LDPE-LAC films in milk were plated as controls. The countable range for $3 \mathrm{M}$ Petrifilm is 25 to $250 \mathrm{cfu}$.

The presence of lipase was determined by assessing the overall activity of potential lipase contaminants in film storage solution (0.1 M, pH 5.0 MES and milk), from films stored at $4^{\circ} \mathrm{C}$ for $21 \mathrm{~d}$ in sterile tubes $(1 \mathrm{~mL} /$

$\mathrm{cm}^{2}$ ). The pNPA assay was prepared and performed as outlined by Bier for lipases (Bier, 1955). The assay was performed at $50^{\circ} \mathrm{C}$ and $\mathrm{pH} 5.0$ to follow the optimum conditions of the purified lactase. The samples from milk and MES storage solution were compared with a blank of storage buffer from LDPE. Activity was calculated from an experimentally determined extinction coefficient $(\varepsilon)$ of $0.147 \mu \mathrm{mol} / \mathrm{mL}$ produced by a standard curve of $p$-nitrophenol $(99 \%)$ and $0.1 M, \mathrm{pH}$ 5.0 MES buffer. The resulting activity in units per milliliter represents $1 \mu \mathrm{mol}$ of pNPA cleaved per minute per milliliter of total assay. Lipase activity of films stored in both $0.1 \mathrm{M}, \mathrm{pH}$ 5.0 MES buffer and UHT skim milk was measured against LDPE as a negative control and $10 \%$ (wt/vol) lipase from Candida rugosa (Sigma-Aldrich) as a positive control.

Assessment of protease contamination of the final dairy product from film preparation was completed with the Protozyme OL reagent tablet from Megazyme. Protozyme OL tablets are used for the assay of endoproteases that are active on collagen. Megazyme Protazyme OL tablets use an azurine-crosslinked collagen unit as a substrate that, when cleaved, produces a blue color. The LDPE was the negative control and $0.5 \%$ (wt/vol) $\alpha$-chymotrypsin from bovine pancreas (Sigma-Aldrich) was the positive control. For each sample, one tablet was hydrated in $1 \mathrm{~mL}$ of $0.1 \mathrm{M}, \mathrm{pH} 5.0$ sodium acetate buffer and stirred for $5 \mathrm{~min}$ at $40^{\circ} \mathrm{C}$. Once hydrated, $1 \mathrm{~mL}$ of milk or MES buffer from the modified films stored at $4^{\circ} \mathrm{C}$ for $21 \mathrm{~d}\left(1 \mathrm{~mL} / \mathrm{cm}^{2}\right)$ was added to the tablet and stirred for $10 \mathrm{~min}$. The reaction was stopped by the addition of $10 \mathrm{~mL}$ of $\mathrm{Na}_{3} \mathrm{PO}_{4} \cdot 12 \mathrm{H}_{2} \mathrm{O}(2 \% \mathrm{wt} / \mathrm{vol}$, $\mathrm{pH}$ 11), and vortexed. The sample was allowed to stand for $5 \mathrm{~min}$ at room temperature and then centrifuged to separate the tablet from supernatant. The supernatant was measured at $590 \mathrm{~nm}$, and was compared with a standard curve provided by Megazyme based on the same assay conditions for a Bioprotease A endoprotease from Aspergillus niger.

All statistical analysis was done on Graphpad Prism software (v. 5.04, Graphpad Software, La Jolla, CA). One-way ANOVA with Tukey's pairwise comparison was done for calculation of statistical difference between samples with a $95 \%$ CI $(P<0.05)$.

The microbial growth in UHT skim milk alone and in contact with film treatments (LDPE, LDPE-GL, LDPE-LAC) was quantified by SPC to determine if our active packaging films influenced the spoilage rate for UHT skim milk. Standard plate counts were performed as indicators over a typical 21-d consumption period for milk (Figure 1). Notable growth was observed after $7 \mathrm{~d}$ of storage for LDPE-GL and LDPE-LAC film variants at 1.33 and $1.55 \log _{10} \mathrm{cfu} / \mathrm{mL}$, respectively, with microbial growth rates analogous for both film variants through $14 \mathrm{~d}$ at 3.44 and $3.46 \log _{10} \mathrm{cfu} / \mathrm{mL}$, respectively. These results suggest that any contamination in the film preparation method was due to the cross-linking step rather than by introduction of microbial contaminants in the enzyme preparation. Purification of the cross-linking reagents (in the current work, cross-linking reagents were used as received without further purification) may prevent the observed microbial growth. Preparation of an active package often requires more procedural steps that can lead to unexpected changes in food stability and quality. After $21 \mathrm{~d}$ of storage, microbial growth was observed in fluid milk stored without any films. Native polyethylene, the negative control, showed no growth or change in colony-forming units per milliliter after $21 \mathrm{~d}$ of storage, further suggesting that any microbial contamination of the active packaging film was introduced by the cross-linking reagent. No differences were seen between growth for LDPE-GL and LDPE-LAC 
until d 21. It should be noted that the aerobic SPC method used here cannot differentiate between spoilage or pathogenic microorganisms, so results represent total microbial growth over the storage period. Microbial growth in milk stored with LDPE-LAC and LDPE-GL films remained under the limit defined by the Pasteurized Milk Ordinance for grade A pasteurized and ultra-pasteurized milk $\left(20,000 \mathrm{cfu} / \mathrm{mL}\right.$ or $4.301 \log _{10}$ cfu/mL; United States Food and Drug Administration, 2011) through $14 \mathrm{~d}$ of storage. These results suggest that the active packaging films developed herein would not increase microbial populations in milk over $14 \mathrm{~d}$ postpackaging, and that purification of cross-linking reagents would likely improve this shelf life. Commercial manufacturing of the reported films should consider use of purified cross-linking reagents to further improve microbial stability.

Commercial enzyme preparations often contain enzymatic impurities (e.g., lipases, proteases) that can adversely affect milk quality. Lipases have been known to produce off-flavors and off-odors, decreasing fluid milk shelf-life and negatively affecting consumer acceptance of dairy products (Santos et al., 2003). Lipase activity in milk or buffer after storage in contact with LDPE-LAC active packaging films was determined using the substrate, pNPA, as an overall indicator of lipase. Lipase activity is reported in units/ per milliliter representing $1 \mu \mathrm{mol}$ cleaved pNPA per minute for every milliliter under the conditions of the assay. The positive control (10\% lipase from Candida rugosa)

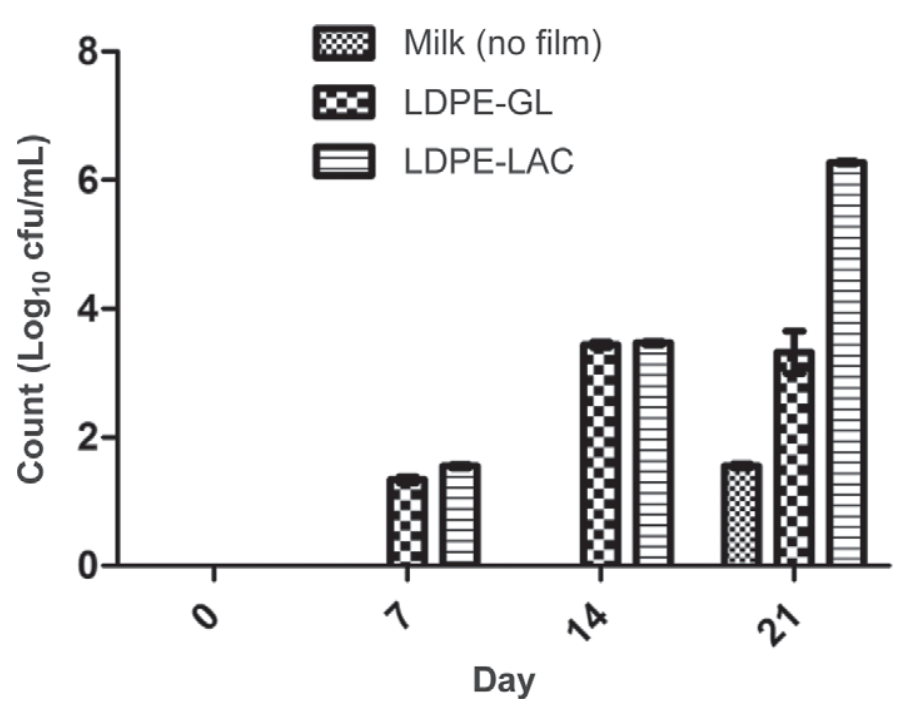

Figure 1. Microbial growth in UHT pasteurized skim milk stored at $4^{\circ} \mathrm{C}$ alone, in contact with low-density polyethylene with glutaraldehyde cross-linking layers (LDPE-GL), and in contact with active packaging film containing lactase (LDPE-LAC), where $\mathrm{n}=3$. Milk stored in contact with native polyethylene exhibited no growth over the course of the study (data not shown). exhibited an expected lipase activity of 0.026 units/ $\mathrm{mL}$, whereas neither milk nor buffer exhibited any significant lipase activity after storage with LDPE-LAC films. Further, no statistically significant difference was observed between the lipase activity of native LDPE (negative control) or LDPE-LAC stored in MES buffer or milk (Figure 2). Lipase activity measurements were taken from both storage buffer and from milk to verify that lipase activity reported was a result of the film preparation and not from lipase naturally occurring in milk. These results suggest that the immobilized lactase active packaging film reported here would not introduce any additional lipase contamination from the film preparation into packaged fluid milk.

Peptides produced by proteolysis of casein from the introduction of protease contaminants, have been reported to impart bitterness and astringency in dairy products (Ma et al., 2003; Santos et al., 2003). Protease activity in milk or buffer after storage in contact with LDPE-LAC films was measured using Megazyme Protazyme OL tablets. Protease activity is reported in units per milliliter representing $1 \mu \mathrm{mol}$ soluble tyrosine produced per minute for every milliliter under the conditions of the assay. The positive control, chymotrypsin, exhibited an expected protease activity of 43.252 units/ $\mathrm{mL}$. The protease activities of native LDPE, as well

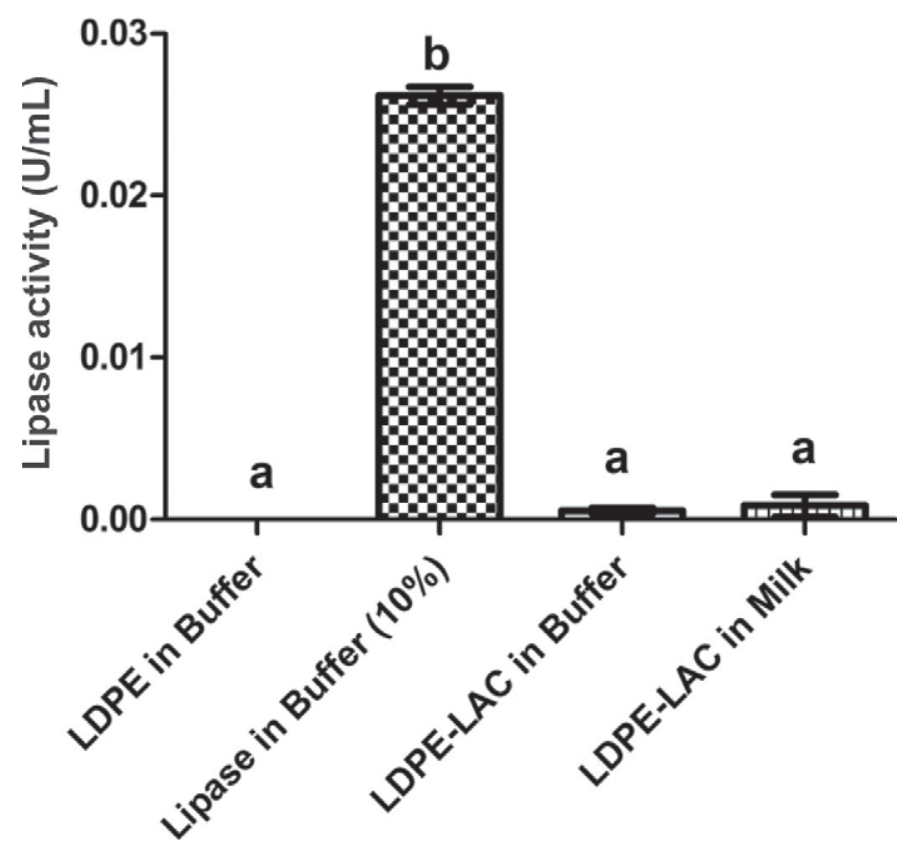

Figure 2. Lipase activity in milk or buffer after storage in contact with LDPE-LAC active packaging films at $4^{\circ} \mathrm{C}$ for $21 \mathrm{~d}$ as determined by p-nitrophenyl acetate assay, where $\mathrm{n}=4$. Native polyethylene and $10 \%$ lipase from Candida rugosa in $0.1 \mathrm{M}, \mathrm{pH} 5.0$ 2-(N-morpholino) ethanesulfonic acid buffer served as negative and positive controls. $\mathrm{LDPE}=$ low-density polyethylene; LAC $=$ lactase. Letters $\mathrm{a}$ and $\mathrm{b}$ indicate significant difference. 


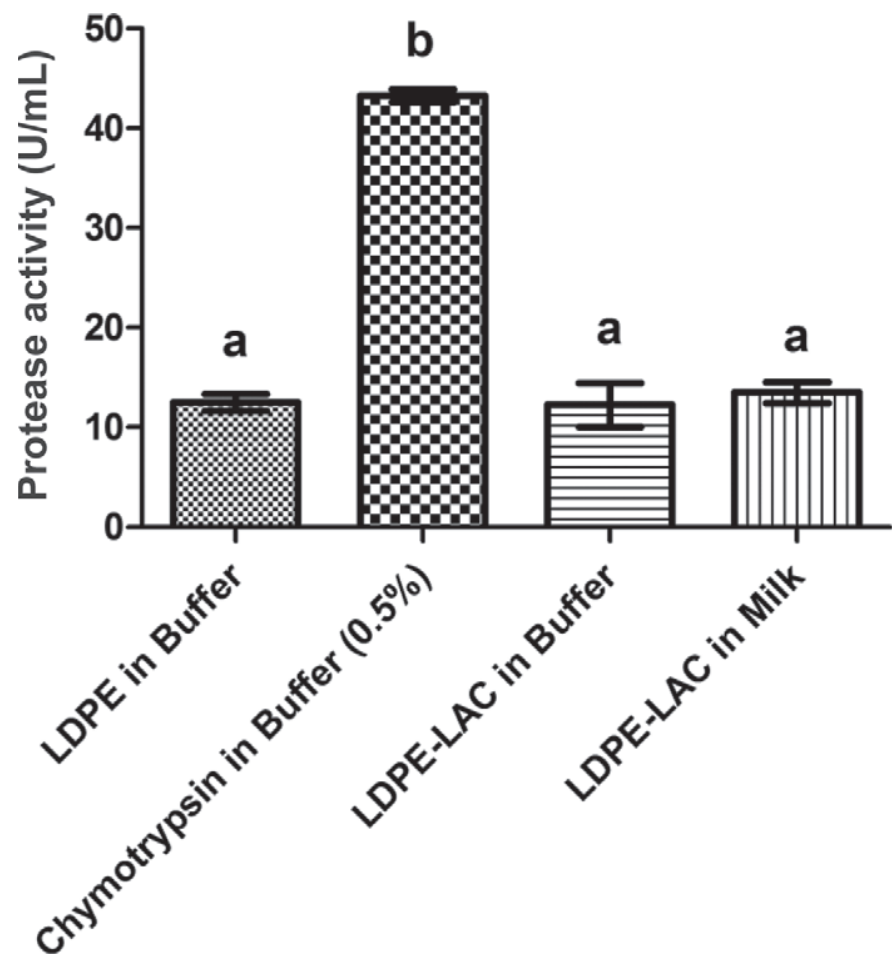

Figure 3. Protease activity in UHT milk or buffer after storage in contact with LDPE-LAC active packaging films at $4^{\circ} \mathrm{C}$ for $21 \mathrm{~d}$ as determined by Megazyme Protazyme assay, where $\mathrm{n}=4$. Native polyethylene and $10 \%$ protease (chymotrypsin) in $0.1 \mathrm{M}, \mathrm{pH} 5.0$ 2-(N-morpholino) ethanesulfonic acid buffer served as negative and positive controls, respectively. LDPE = low-density polyethylene; LAC $=$ lactase. Letters a and $\mathrm{b}$ indicate significant difference.

as that of MES buffer and milk stored in contact with LDPE-LAC films, were equivalent at 12.500, 12.250, and 13.500 units $/ \mathrm{mL}$, respectively (Figure 3 ). These results suggest that the LDPE-LAC films did not introduce protease contamination to the fluid milk.

The goal of the reported immobilized lactase active packaging technology is to link the lactase to LDPE via a covalent cross-linking chemistry (Goddard et al., 2007; Wong et al., 2013). Protein migration was measured by the comparison of the protein contents of the storage solution and LDPE-LAC film as indicators of the stability of the covalent immobilization chemistry. Protein migration was reported as the total protein mass in storage buffers and on films at $\mathrm{d} 0$ and after $49 \mathrm{~d}$ of storage (Figure 4). No significant difference was observed in the protein contents of the MES storage buffer between d 0 and 49. Likewise, no significant difference in protein content on the LDPE-LAC films was observed at d 0 and 49 (Figure 4). These results indicate that the lactase immobilization chemistry was covalent and that no protein migrated from the film over the 49-d long-term storage period. Establishing that active agents and cross-linking reagents are unlike-

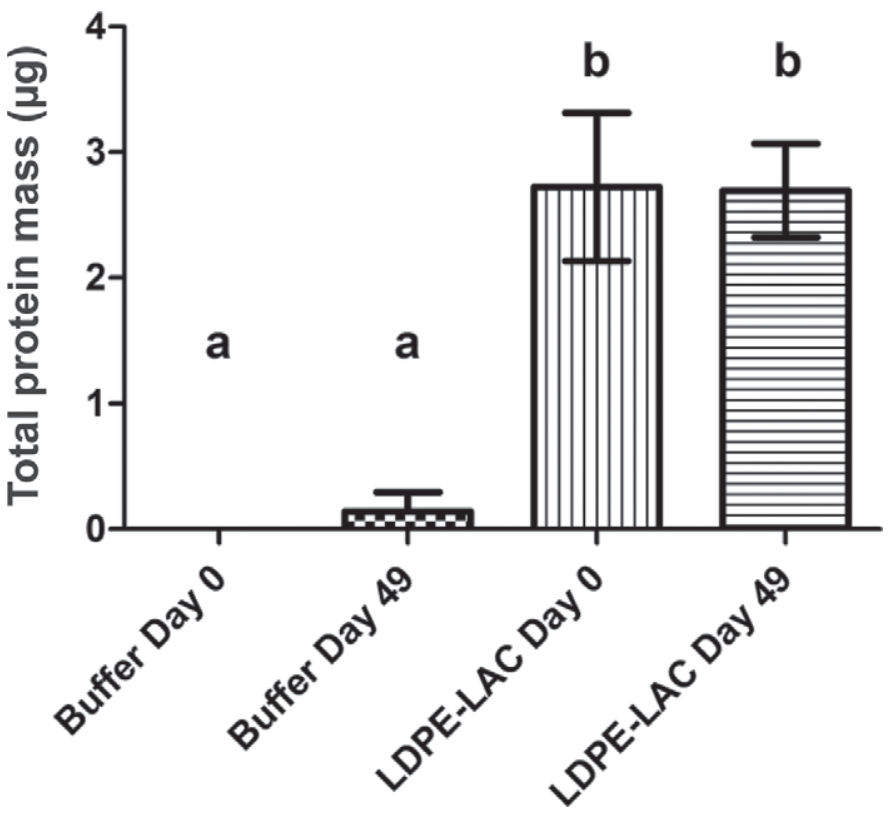

Figure 4. Stability of lactase immobilized on active packaging films. Migration of protein after storage of LDPE-LAC films in 2 -( $N$-morpholino) ethanesulfonic acid (MES) buffer for $49 \mathrm{~d}$ at $4^{\circ} \mathrm{C}$ as determined by bicinchoninic acid assay, where $\mathrm{n}=4$. Buffer results (left) represent protein content in MES storage buffer initially and after $49 \mathrm{~d}$ storage with films. LDPE-LAC results (right) represent amount of immobilized protein on LDPE-LAC films initially and after $49 \mathrm{~d}$ of storage. LDPE = low-density polyethylene; LAC = lactase. Letters $\mathrm{a}$ and $\mathrm{b}$ indicate significant difference.

ly to migrate to the food, such reagents would require regulatory approval as indirect additives rather than as direct additives, a potential labeling and regulatory advantage.

The retention of lactase activity of the immobilized lactase active packaging films was measured using the ONPG assay after $8 \mathrm{wk}$ of storage in both wet (MES buffer at $\left.4^{\circ} \mathrm{C}\right)$ and dry $(15 \%$ relative humidity at $25^{\circ} \mathrm{C}$ ) storage conditions. Activity measurements are expressed as percent activity retention normalized to the activity of freshly prepared LDPE-LAC films (Figure 5). An initial decrease in activity was observed for films stored in both dry and wet conditions after 1 wk of storage. Films stored in MES buffer retained up to $78.57 \%$ of original film activity, whereas films in dry conditions dropped to $63.24 \%$ activity. Retained activity of films stored in dry conditions was at $13.41 \%$ of the original activity after $8 \mathrm{wk}$ of storage, about one-fourth of the activity of films stored in contact with buffer (62.52\%) after 8 wk of storage. Although some activity was retained after dry film storage, these results indicated that storage in the presence of buffer helped to maintain the structural integrity of the enzyme immobilized on the modified film. Alternative storage conditions such as higher relative humidity, 


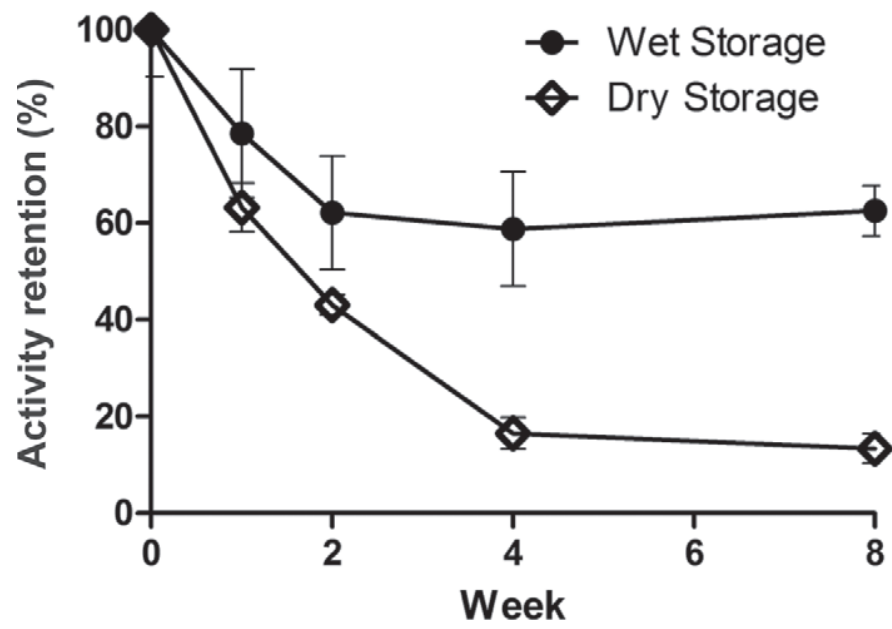

Figure 5. Activity retention of immobilized lactase active packaging films under wet [2-( $N$-morpholino $)$ ethanesulfonic acid buffer] and dry storage conditions. Lactase activities are reported as percent retained activity, normalized to lactase activity of freshly prepared LDPE-LAC films where $\mathrm{n}=4$. LDPE $=$ low-density polyethylene; $\mathrm{LAC}=$ lactase.

use of freeze-dried enzyme preparations, or highly hydrophilic cross-linking reagents may improve activity retention of immobilized enzyme active packaging films stored in dry conditions.

Active food packaging technologies offer the ability to achieve a desired technical effect on a packaged food. A hurdle in demonstrating the commercial potential of active packaging materials is the often overlooked potential for unanticipated technical effects by the material on the packaged food due to the extra preparation required. In this work, we analyzed the stability and quality of UHT skim milk after storage in contact with an immobilized lactase active packaging film using standard protease, lipase, and lactase activity measurements, as well as SPC and protein migration assays. Standard plate counts indicated that microbial growth occurred in the samples in contact with the immobilized lactase films after $7 \mathrm{~d}$ of storage, but remained under the Pasteurized Milk Ordinance regulation for the colony-forming units spoilage threshold until after $14 \mathrm{~d}$ of storage. It was determined that the cross-linkers were the primary source of microbial contamination, suggesting that film preparation should use purified reagents and cross-linkers. Protease and lipase activity assays indicated that no additional protease or lipase was added to the food system. Protein migration assays indicated that no protein migrated from the film into the storage buffer over the course of the storage study, suggesting that the lactase was covalently bound to the active packaging film. Demonstrating that an active agent is unlikely to migrate to the food product is a potential regulatory benefit, as the cross-linkers and active agents used in nonmigratory active packaging technologies require food contact notification for an indirect additive, whereas those used in migratory active packaging technologies require approval for a direct additive (Koontz, 2012). Films stored under wet conditions retained up to $62.52 \%$ activity, whereas those stored in dry conditions retained only $13.41 \%$ activity after 8 wk of storage, indicating that alternative immobilization chemistries or storage conditions should be considered to improve dry storage stability. Overall, the immobilized lactase active packaging films exhibited significant retained activity after up to 8 wk of storage, in which the active agent (lactase) was found to be nonmigratory and did not significantly affect microbial growth. Formal sensory evaluations would need to be performed before commercial adoption of the film.

\section{ACKNOWLEDGMENTS}

This work was funded in part by Dairy Management Inc. as managed by Dairy Research Inst. (Rosemont, IL). The authors thank Joey N. Talbert, Samuel Alcaine, and Vivian Chong (Department of Food Science at the University of Massachusetts, Amherst) for their assistance with methods development.

\section{REFERENCES}

Adhikari, K., L. M. Dooley, E. Chambers, and N. Bhumiratana. 2010. Sensory characteristics of commercial lactose-free milks manufactured in the United States. Lebenson. Wiss. Technol. 43:113-118.

Albayrak, N. 2002. Production of galacto-oligosaccharides from lactose by Aspergillus oryzae $\beta$-galactosidase immobilized on cotton cloth. Biotechnol. Bioeng. 77:8-19.

AOAC International. 2002. Official Methods of Analysis. AOAC International, Gaithersburg, MD.

Bier, M. 1955. Lipases. Methods Enzymol. 1:627-642.

Chapman, K. W., H. Lawless, and K. Boor. 2001. Quantitative descriptive analysis and principal component analysis for sensory characterization of ultrapasteurized milk. J. Dairy Sci. 84:12-20.

Fernández, A., D. Cava, M. J. Ocio, and J. M. Lagarón. 2008. Perspectives for biocatalysts in food packaging. Trends Food Sci. Technol. 19:198-206.

Freitas, F., G. Ribeiro, G. Brandao, and V. Cardoso. 2011. A comparison of the kinetic properties of free and immobilized Aspergillus oryzae $\beta$-galactosidase. Biochem. Eng. J. 58-59:33-38.

Goddard, J. M., J. N. Talbert, and J. H. Hotchkiss. 2007. Covalent attachment of lactase to low-density polyethylene films. J. Food Sci. 72:E036-E041.

Grosová, Z., M. Rosenberg, M. Rebros, M. Sipocz, and B. Sedlackova. 2008. Entrapment of $\beta$-galactosidase in polyvinylalcohol hydrogel. Biotechnol. Lett. 30:763-767.

Hansen, A. P., and D. K. Arora. 1990. Loss of flavor compounds from aseptically processed food-products packaged in aseptic containers. ACS Symp. Ser. 423:318-332.

Husain, Q. 2010. $\beta$-Galactosidases and their potential applications: A review. Crit. Rev. Biotechnol. 30:41-62.

Institute of Medicine (US) Committee on Food Chemicals Codex. 2003. Food Chemicals Codex. Natl. Acad. Press, Washington, DC.

Koontz, J. 2012. Active packaging materials to inhibit lipid oxidation: US regulatory framework. Intern. News Fats Oils Relat. Mater. 23:598-600. 
Ma, Y., M. Santos, and D. M. Barbano. 2003. Effect of $\mathrm{CO}_{2}$ addition to raw milk on proteolysis and lipolysis at $4^{\circ} \mathrm{C}$. J. Dairy Sci. 86:1616-1631.

Mahoney, K. W., J. N. Talbert, and J. M. Goddard. 2013. Effect of polyethylene glycol tether size and chemistry on the attachment of lactase to polyethylene films. J. Appl. Polym. Sci. 127:1203-1210.

Martin, N. H., N. R. Carey, S. C. Murphy, M. Wiedmann, and K. J. Boor. 2012. A decade of improvement: New York State fluid milk quality. J. Dairy Sci. 95:7384-7390.

Matthews, S. B., J. Waud, A. Roberts, and A. Campbell. 2005. Systemic lactose intolerance: A new perspective on an old problem. Postgrad. Med. J. 81:167-173.

Santos, M. V., Y. Ma, Z. Caplan, and D. M. Barbano. 2003. Sensory threshold of off-flavors caused by proteolysis and lipolysis in milk. J. Dairy Sci. 86:1601-1607.
Swallow, D. M. 2003. Genetics of lactase persistence and lactose intolerance. Annu. Rev. Genet. 37:197-219.

United States Food and Drug Administration. 2011. Grade "A" Pasteurized Milk Ordinance. US Dept. of Health and Human Services, Public Health Service, Food and Drug Administration, Washington, DC.

Vermeiren, L., F. Devlieghere, M. Van Beest, N. De Kruijf, and J. Debevere. 1999. Developments in the active packaging of foods. Trends Food Sci. Technol. 10:77-86.

Vesa, T. H., P. Marteau, and R. Korpela. 2000. Lactose intolerance. J. Am. Coll. Nutr. 19:165S-175S.

Wong, D. E., J. N. Talbert, and J. M. Goddard. 2013. Layer by layer assembly of a biocatalytic packaging film: Lactase covalently bound to low-density polyethylene. J. Food Sci. 78:E853-860. 